\title{
CRYSTAL MORPHOLOGY AND GROWTH RATE OF NAPHTHALENE IN VARIOUS PROCESSES INVOLVING SUPERCRITICAL CARBON DIOXIDE
}

\author{
C. Y. TAI and C.-S. CHENG \\ Department of Chemical Engineering, National Taiwan University, Taipei, Taiwan
}

\begin{abstract}
A $\mathrm{n}$ experimental apparatus was designed to investigate the crystal morphology and growth rate of naphthalene crystals grown in various processes using supercritical carbon dioxide, including SCG (single crystal growth), SESS (slow expansion of supercritical solution), and RESS (rapid expansion of supercritical solution). Photographs were taken to identify crystal habits. The growth rates of naphthalene in the SCG and SESS processes were measured and compared with those in a RESS process.
\end{abstract}

Keywords: crystal morphology; growth rate; supercritical $\mathrm{CO}_{2}$; RESS process; SESS process; single crystal growth

\section{INTRODUCTION}

Recently, the RESS process was applied to produce small, monodisperse particles, which utilized the distinctive features of a supercritical solution for its fast propagation of pressure perturbation and high supersaturation ratio. The former leads to uniform supersaturation and hence to narrow particle size distribution; the latter, to small particles. The crystals nucleate instantly with limited growth during the expansion step $^{1,2}$. Thus, the phenomena of nucleation from a supercritical fluid has been intensively investigated ${ }^{3-5}$, leaving the study of crystal growth neglected. However, Mohamed et $a l^{3}$ produced fairly large naphthalene crystals by expanding a supercritical carbon dioxide solution through a nozzle. The size of naphthalene crystals so obtained was over $200 \mu \mathrm{m}$ in some cases. Apparently, the naphthalene crystals were subject to substantial growth during the expansion process.

Meanwhile, Chimowitz and his co-workers ${ }^{6,7}$ developed a separation process exploiting the cross-over region, which is a distinguishing feature of supercritical fluids and concerns the solute solubility. In the process, the solutes deposited under a much weaker supersaturation as compared with the RESS process. Therefore, the particles produced have a chance to grow bigger. Later, using a batch crystallizer to study the crystallization mechanism in a supercritical carbon dioxide solution, Tavana and Randolph $^{8}$ confirmed the validity of the conventional concept that the crystals are formed by nucleation and subsequent growth. The crystal growth rate of benzoic acid in supercritical carbon dioxide solution was estimated to be of the same order of magnitude as crystal growth in aqueous media.

To study the crystal growth from supercritical solution more systematically, Tai and Cheng 9 set up an apparatus, which can be used to observe the growth phenomenon and to measure the growth rate of naphthalene crystal growing in a supercritical carbon dioxide solution. The pressure, temperature, supersaturation, and relative velocity between solution and crystal was varied to investigate their effects on the crystal morphology and growth rate. Their experimental work was later extended to SESS and RESS processes with a minor modification of the apparatus. The supersaturation is generated by adjusting temperature in the SCG process and by releasing pressure in the SESS and RESS processes. The supersaturation level is high in the RESS process, and moderate to low in the SESS and SCG processes. Thus, a different crystal morphology and growth rate would be expected for the crystals generated from the various modes of operation. The aim of this report is to compare the results obtained in the series of growth experiments.

\section{EXPERIMENTAL}

The design principle of the apparatus used in this experiment is similar to that of growing crystals from liquid solution ${ }^{10}$. The set-up was able to measure the solubilities of solid materials, to observe growth phenomena, and to measure growth rate in supercritical carbon dioxide. The major part of the apparatus, shown schematically in Figure 1, is a closed loop consisting of a growth cell for growing crystals, an extractor for supplying solute, and a piston pump for circulating solution. In the extractor, a crystal bed of ground naphthalene (Wako, reagent grade) with a dimension $0.018 \mathrm{~m} \times 0.25 \mathrm{~m}$ was packed. The growth cell is a jacketed liquid-level gauge (Jerguson, Model 18-T-30) with viewing windows. The circulation pump is a variable-stroke dual-piston type, a Milton Roy Minipump and a Clark-Cooper pump for low and high circulation rates, respectively. The pipeline of the closed 


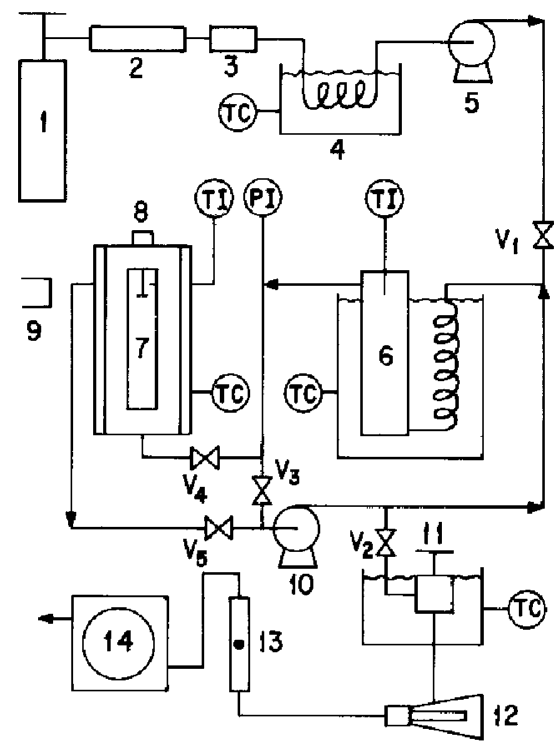

Figure 1. Apparatus for the experiments of crystallization from supercritical carbon dioxide solution. (1) Carbon dioxide cylinder; (2) Silica-gelbed; (3) Filter; (4) Cooler; (5) Feeding pump; (6) Extractor; (7) Crystal growth cell; (8) Needle to fix seed crystal; (9) Microscope;(10) Circulation pump; (11) Expansion valve; (12) Crystal collector; (13) Flowmeter; (14) Wet test meter; PI, Pressure indicator; TI, Temperature indicator; TC, Temperature controller; $\mathrm{V}_{1}, \mathrm{~V}_{2}, \mathrm{~V} 3, \mathrm{~V}_{4}, \mathrm{~V}_{5}$, Ball valves.

loop was built of $1 / 4^{\prime \prime}$ O.D. stainless steel tubes. In the SCG and SESS experiments, the valve $V_{3}$ was closed and the total volume of the closed loop is about $3.5 \times 10^{-4} \mathrm{~m}^{3}$. On the other hand, the valves $V_{4}$ and $V_{5}$ were closed for the RESS experiment, and the total volume of the closed loop excluding the growth cell is around $1.5 \times 10^{-4} \mathrm{~m}^{3}$.

The seed crystals of naphthalene for the SCG experiment were prepared from ethanol solution; several small crystals obtained by evaporating alcohol were introduced into a slightly supersaturated ethanol solution at room temperature to induce nucleation, and the induced nuclei were allowed to grow without stirring. Well-grown crystals, as shown in Figure 2, so prepared were bounded by $\{001\},\left\{20^{-1}\right\}$ and $\{110\}$ faces, the same morphology as that reported by Wells ${ }^{11}$. A seed crystal of $1.5 \times 10^{-3} \mathrm{~m}$ was chosen and glued on the tip of a needle, which was then screwed into the growth cell. The system was ready for the growth experiment. The

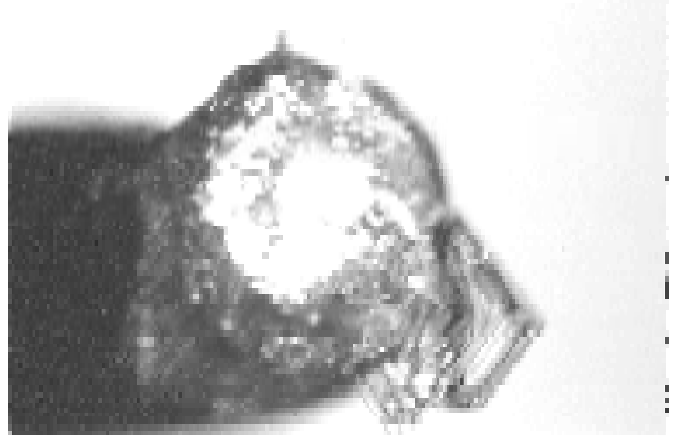

Figure 3. Development of individuals and sprouting of plates for naphthalene crystals from supercriticalCO $\mathrm{CO}_{2}$ solution.

detailed procedure of measuring the solubility and the growth rate of a single crystal is described elsewhere?. It should be noted that the supersaturation for single crystal growth was generated by heating, i.e., the temperature in the growth cell was higher than that in the extractor, because the system was operated in the retrograde region where higher temperature causes lower solubility.

In the SESS experiment, carbon dioxide was first introduced to the closed loop and circulated to saturate the supercritical carbon dioxide solution with naphthalene at desired pressure and temperature. Then the valve $V_{2}$ was opened to release the supercritical fluid through the expansion valve (Autoclave, Model 30 VRMM) at a rate of $2-5 \mathrm{lit} / \mathrm{min}$ measured at $1 \mathrm{~atm}$. During the expansion period, the pressure and temperature versus time were recorded and the solid formation in the growth cell, either on the tip of the needle or on the glass wall, was detected by visual examination. Then photographs of the crystal were

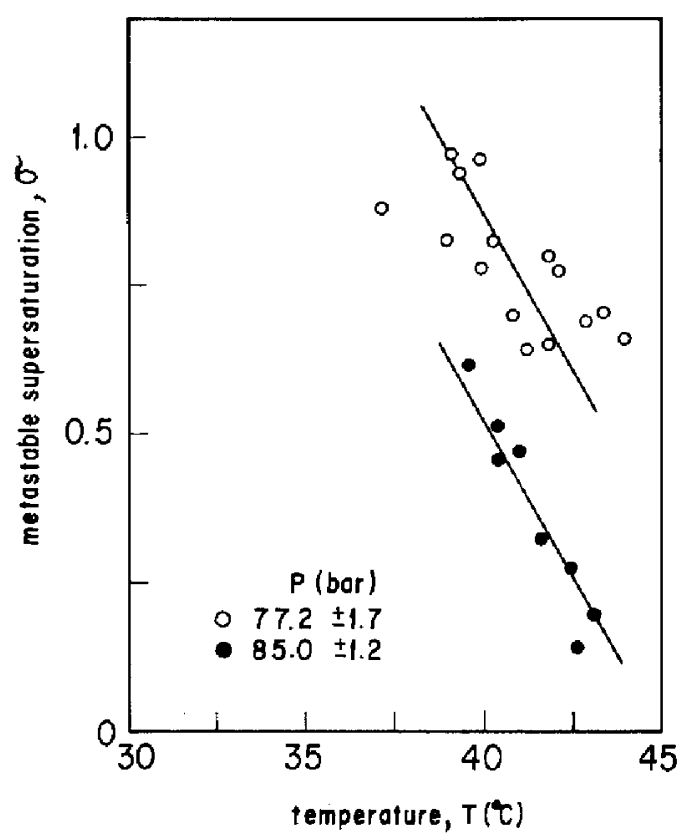

Figure 4. Effect of pressure and temperature on metastable supersaturation for the naphthalene/supercriticalCO $\mathrm{CO}_{2}$ system. 


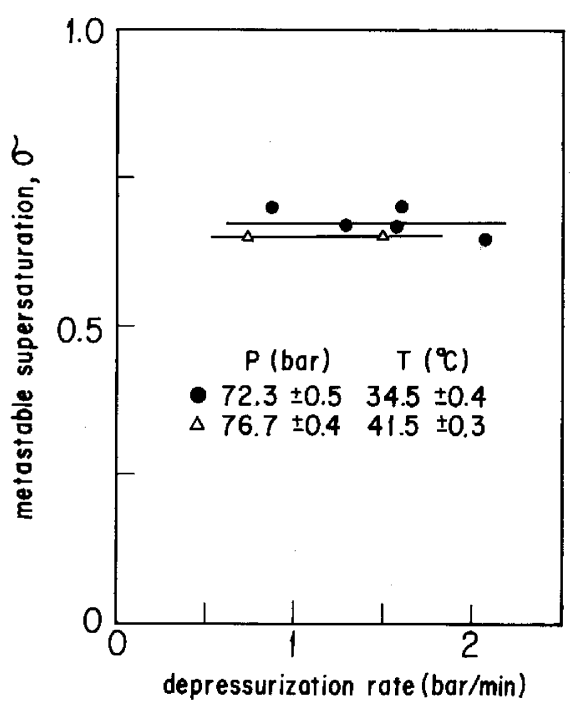

Figure 5. Effect of depressurization rate on the metastable supersaturation of naphthalene in near-critical and supercritical $\mathrm{CO}_{2}$ solution.

taken during a certain growing time using a stereo microscope (Nikon, Model SMZ-10 ). Thus, the crystal growth rates were estimated. In this experiment, various pre-expansion pressures, temperatures, and solution concentrations were tested.

In the RESS experiment with the valve $V_{4}$ and $V_{5}$ closed, carbon dioxide becomes saturated in the closed loop containing only the extractor under desired the temperature and pressure. Then the valve $V_{2}$ was opened to expand the supercritical solution into the crystal collector. Meanwhile, the valve $\mathrm{V}_{1}$ was opened to maintain the pressure and temperature steady in the extractor by supplying carbon dioxide through valve $V_{1}$. Photographs of the collected crystals were taken.

\section{RESULTS AND DISCUSSION Crystal Morphology and Growth Phenomena}

Single crystal growth

There are two distinct features for the crystal growth of a naphthalene seed in a supercritical carbon dioxide solution, as seen in Figure 3. First, many small individual crystals with light-reflecting faces developed on the seed

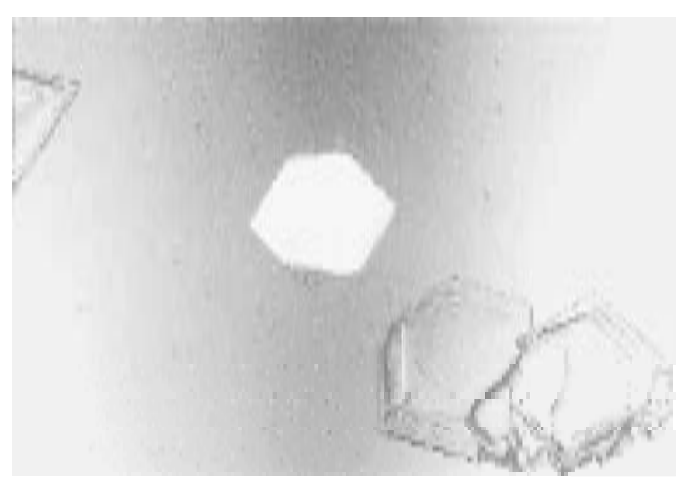

Figure 6. Circular macrosteps on the nucleated naphthaleneplates from supercriticalCO $\mathrm{CO}_{2}$ solution in SESS experiment.

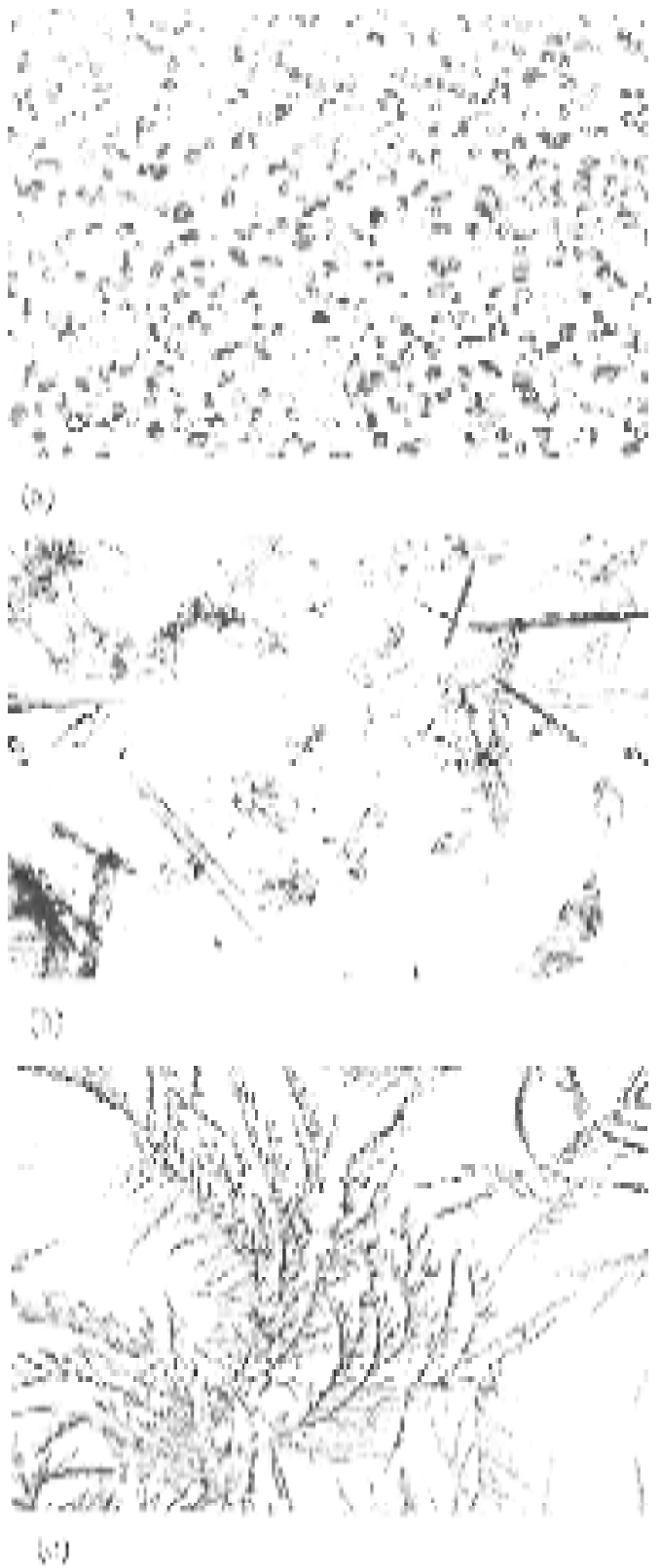

Figure 7. Nucleated naphthalene granules(a), platesnd needles(b), and dendrites (c) from supercriticalCO ${ }_{2}$ solution in RESS experiment.

crystal, which had been partially dissolved to become a hemi-ellipsoid before the solution became saturated. Second, plates sprouted from some of the individual crystals, which located away from the pole of the hemiellipsoid.

The crystal faces of the individuals might change from facet growth to hopper growth when they grew bigger. Critical sizes for the hopper growth are in the range of $3 \times 10^{-4}$ to $7 \times 10^{-4} \mathrm{~m}$, depending on the saturation and solution velocity. Higher supersaturation and lower solution velocity rendered the critical size smaller. One interesting growth phenomenon concerning the sprouted plates is that the lateral faces of the plates might grow stably to remain smooth, or unstably to become zigzag or dendritic.

The mechanism and kinetics of the two types of growth, individuals and sprouted plates, have been 
Table 1. Crystal habits and granule size of nucleated naphthalenecrystals from supercriticalCO $\mathrm{CO}_{2}$ in the RESS experiments.

\begin{tabular}{|c|c|c|c|c|c|c|c|c|c|}
\hline \multirow{2}{*}{$\begin{array}{l}P_{1} \\
\text { (bar) }\end{array}$} & \multirow{2}{*}{$\begin{array}{c}T_{1} \\
\left({ }^{\circ} \mathrm{C}\right)\end{array}$} & \multirow{2}{*}{$\begin{array}{c}C_{1} \\
(\mathrm{~g} / 100 \mathrm{~g})\end{array}$} & \multirow{2}{*}{$\begin{array}{c}T_{2} \\
\left({ }^{\circ} \mathrm{C}\right)\end{array}$} & \multirow{2}{*}{$\underset{(1 / \mathrm{min})}{Q_{\text {ave }}}$} & \multicolumn{4}{|c|}{ Crystal habita } & \multirow{2}{*}{$\begin{array}{l}\text { Granule size } \\
(\mu \mathrm{m})\end{array}$} \\
\hline & & & & & $\mathrm{g}$ & $\mathrm{p}$ & $\mathrm{n}$ & $\mathrm{d}$ & \\
\hline \multirow[t]{3}{*}{76.9} & 35.5 & 0.265 & 28.8 & 2.8 & ๑ & ๑ & ○ & $\odot$ & $20-200$ \\
\hline & 39.9 & 0.175 & 30.0 & 3.5 & ๑ & ๑ & ๑ & ๑) & $50-400$ \\
\hline & 45.0 & 0.169 & 30.5 & 2.0 & () & () & (๑) & () & $100-150$ \\
\hline \multirow[t]{2}{*}{83.8} & 39.0 & 0.605 & 27.0 & 2.2 & ๑ & ๑ & & ๑) & - \\
\hline & 44.9 & 0.282 & 27.5 & 2.1 & ๑ & & ๑ & ๑) & - \\
\hline
\end{tabular}

${ }^{\mathrm{a}} \mathrm{g}=$ granule, $\mathrm{p}=$ plate, $\mathrm{n}=$ needle, $\mathrm{d}=$ dendrite

$P_{1}$ pre-expansion pressure

$T_{1}$ pre -expansion temperature

$T_{2}$ post-expansiontemperature

$Q_{\text {ave }}$ discharge rate

discussed by Tai and Cheng9. They conclude that the growth of naphthalene crystals from supercritical solution shows characteristics similar to liquid-solution growth rather than vapour growth.

\section{Slow expansion of supercritical solution}

For the slow expansion experiment the metastable supersaturation, i.e., the lowest supersaturation for the formation of nuclei detected by visual examination, was plotted against temperature at which nuclei were detected, as shown in Figure 4. It is clear that the metastable supersaturation depends on the temperature and pressure. However, the metastable supersaturation is independent of depressurization rate between 0.5 and $2 \mathrm{bar} / \mathrm{min}$ as illustrated in Figure 5.

The morphology of naphthalene crystals, as shown in Figure 6, is of hexagonal plates with circular, or sometimes irregular, macrosteps to form a hopper structure, which is similar to that of an individual crystal developed from a seed crystal. The size of the hexagonal plate is between 0.25 to $1.0 \times 10^{-3} \mathrm{~m}$. Apparently, the generated nuclei were subject to growth for a long period of time.

\section{Rapid expansion of supercritical solution}

The morphology of naphthalene precipitated in the crystal collector after rapid expansion is shown in Figure 7 and summarized in Table 1 for two different pre-expansion pressures. When the pre-expansion

Table 2. Estiamted growth rate of various crystals in theRESS proces.

\begin{tabular}{lccccccc}
\hline & \multicolumn{3}{c}{ Nozzle } & & & & \\
\cline { 2 - 4 } Crystal & $\begin{array}{c}\text { diameter } \\
(\mu \mathrm{m})\end{array}$ & $\begin{array}{c}\text { length } \\
(\mathrm{mm})\end{array}$ & $\begin{array}{c}Y_{1}^{\mathrm{a}} \\
\left(\times 10^{-3}\right)\end{array}$ & $\begin{array}{c}L_{\mathrm{m}} \\
(\mu \mathrm{m})\end{array}$ & $\begin{array}{c}\mathrm{R}^{\mathrm{b}} \\
\left(\mathrm{m} \mathrm{s}^{-1}\right)\end{array}$ & Reference \\
\hline Lovastatin & 25 & 0.25 & 0.055 & 0.26 & 0.026 & {$[13]$} \\
Benzoic acid & 50 & 0.20 & 1.7 & 8.1 & 0.81 & {$[4]$} \\
Phenanthrene & 25 & 0.25 & 2.1 & 15 & 1.5 & {$[14]$} \\
Naphthalene & 25 & 0.25 & 26 & 225 & 22.5 & {$[3]$} \\
& metering valve & - & 400 & 40 & this work \\
\hline
\end{tabular}

\footnotetext{
${ }^{a}$ mole fraction of solute before expansion

b the maximum particle sizes $\left(L_{\mathrm{m}}\right)$ divided by the residence time of fluid in the expansion to obtain the growth rates; the residencetime was taken $^{15}$ as $10^{-5} \mathrm{~s}$.
}

pressure was set at 76.9 bar, crystal habits of granule, plate, needle, and dendrite form were observed independent of the pre-expansion temperature. However, when the pre-expansion pressure was set at 83.8 bar, needle and plate crystals were missing for the preexpansion temperature of $39.0^{\circ} \mathrm{C}$ and $44.9^{\circ} \mathrm{C}$ respectively. Thus, the crystal morphology was influenced by the pre-expansion pressure and temperature. The different crystal habits exhibited by RESS prepared particles implys varying growth rates on individual crystal faces, even during the extremely short time for growth. The crystal size of precipitated naphthalene is listed in Table 1, with the largest size up to $400 \mu \mathrm{m}$. It is an unusual size of crystal obtained from a RESS process. For example, the ceramic powders produced from the expansion of supercritical water are submicrons in size ${ }^{12}$; even organic materials precipitated from the expansion of supercritical carbon dioxide are usually small ${ }^{2}$. However, Mohamed et al $^{3}$ obtained fairly large naphthalene crystals, which is similar to the present result, up to $225 \mu \mathrm{m}$. The crystal size and estimated growth rate of naphthalene of some organics precipitated from the expansion of supercritical solution are tabulated in Table 2. It is noted that the crystal size and growth rate of naphthalene crystal are much larger than other crystals. One possible reason is that a liquid phase was formed during expansion to give larger particle size; the other may be that the solute clusters experienced an unusually high rate of agglomeration in the expansion region due to high supersaturation.

Table 3. Crystal growth rate obtained by various growth techniques from supercriticalCO .

\begin{tabular}{lccc}
\hline Crystal & Technique & \multicolumn{1}{c}{$\begin{array}{c}\text { Growth rate } \\
(\mathrm{m} / \mathrm{s})\end{array}$} & Reference \\
\hline $\begin{array}{l}\text { Naphthalene } \\
\text { Napthalene, }\end{array}$ & SCG & $\begin{array}{c}3 \times 10^{-9} \sim 9 \times 10^{-8} \\
8 \times 10^{-9} \sim 4 \times 10^{-7}\end{array}$ & $\begin{array}{c}\text { this work } \\
\text { this work } \\
\text { Benzoic acid }\end{array}$ \\
$\begin{array}{l}\text { Napthalene, } \\
\text { Benz }\end{array}$ & RESS & $0.02 \sim 23$ & seeTable 2
\end{tabular}

Benzoic acid,

Phenanthrene,

Lovastatin 


\section{Comparison of the Growth Processes}

\section{Width of metastable region}

There are two methods to generate the supersaturation of a supercritical solution, i.e., by adjusting the system pressure (depressurization) or temperature (heating or cooling, depending on the nature of solubility). The former was employed in the SESS process and the later in the SCG process. However, the width of metastable region is quite different for the processes. At $45^{\circ} \mathrm{C}$ and 84 bar, the supersaturation $\sigma$ (relative supersaturation) was up to 0.1 for the depressurization, but 0.4 for the heating. This means that a pressure disturbance induces primary nucleation more easily than a temperature disturbance.

\section{Crystal growth rate}

Although the technique for estimating the crystal growth rate is different for the three processes, the crystal growth rates are all expressed as the change of a specified linear dimension: the advancement of a crystal face in the SCG process; the change of a longest linear dimension in the SESS process; the maximum size divided by the growing time in the RESS process. A comparison of crystal growth rates obtained by various techniques from supercritical carbon dioxide solution is presented in Table 3. The growth rate of a naphthalene single crystal is approximately between $10^{-9}$ and $10^{-7} \mathrm{~m} \mathrm{~s}^{-1}$, which is close to the rate of crystal growth from aqueous solution. The growth rates of naphthalene crystal obtained by the SESS process is of the same order of magnitude as that obtained by single crystal technique. Joined this group in the order of magnitude is the growth rate of benzoic acid crystals estimated from a batch experiment conducted by Tavana and Randolph ${ }^{8}$. Therefore, their batch experiment is probably similar to the slow expansion process. The growth rates for several organics precipitated in the RESS process are much higher, by 5 order of magnitude at least. Apparently, the growth mechanism of the RESS process is different from that of other processes.

\section{CONCLUSION}

An apparatus was designed to study the crystal growth of naphthalene from supercritical solution for different processes, including SCG, SESS, and RESS. The metastable region for crystal growth was wider by adjusting the temperature than the pressure; the former was used to obtain the supersaturation in the SCG process and the later in the SESS process. Different crystal morphologies were obtained from various processes and under different operating conditions in the same process. The particle size of naphthalene crystal varied considerably at different operating conditions in the RESS process.

\section{REFERENCES}

1. Krukonis, V. J., 1984, 'Supercriticalfluid nucleation of difficult-tocomminute solids, AIChEmeeting, San Francisco, November, 1984, paper $140 \mathrm{f}$.

2. Tom, J. W. and Debenedetti, P. G., 1991, J AerosolSci 22 (5): 555.

3. Mohamed, R. S., Debenedetti, P. G., and Prud'homme, R. K., 1989, AIChEJ, 35 (2): 325.

4. Berends, E. M., Bruinsma, O. S. L., and van Rosmalen, G. M., 1993, J Crystal Growth, 128: 50.

5. Liang, M.-T., The Application of nucleation theories to the particle formation in expansion of supercriticalsolutions, In third Int Symp on Supercritical Fluids, Strasbourg, France October, 1994. Tome 3, 247-252,

6. Chimowitz, E. H. and Pennisi, K. J., 1986, AIChEJ, 32 (10): 1665.

7. Chimowitz, E. H. and Kelley, F. D., 1989, AIChEJ, 35 (6): 981.

8. Tavana, A and Randolph, A. D., 1989 AIChE J, 35 (10): 1625.

9. Tai, C. Y. and Cheng, C.-S., 1995, AIChE J, 41 (10): 2227.

10. Tai, C. Y., Cheng C.-S. , and Huang, Y.-C. , 1992, J Crystal Growth, 123: 236.

11. Wells, A. F., 1946, Phil Mag, 37: 184.

12. Matson, D. W., Petersen, R. C., and Smith, R. D., 1987, Advances in Ceramic, 21: 109.

13. Mohamed, R. S., Halverson D. S., Debeenedetti, P. G., and Prud'homme, R. K., 1989, ACS Symp Ser No 406, 355.

14. Shaub, G. R., Brennecke,J. F., and Mccready, M. J., 1991, In Proc 2nd Int Symp on Supercritical Fluids, 338.

15. Peterson, R. C., Matson, D. W., and Smith, R. D., 1986, J Am Chem Soc, 108: 2100.

\section{ACKNOWLEDGEMENT}

The author gratefully acknowledge the financial support of National Science Council of the Republic of China.

\section{ADDRESS}

Correspondence concerning this paper should be addressed to Dr C. Y. Tai, Department of Chemical Engineering, National Taiwan University, Tapei, Taiwan. 